\title{
ALFABETIZAÇÃO CIENTIFICA E UMA DISCUSSÃO MEDIADA POR FILME DE BILHETERIA CONTEMPORÂNEO
}

\author{
Manuella Candéo1, Rosemari Castilho Monteiro Foggiatto Silveira², \\ Eloíza Aparecida Silva Ávila de Matos $^{3}$ \\ Programa de Pós-graduação em Educação Científica e Tecnológica \\ Universidade Técnica Federal do Paraná (UTFPR) \\ Avenida Monteiro Lobato, s/n, Km 4. Ponta Grossa-PR. CEP: 84016-210
}

\begin{abstract}
RESUMO
0 presente artigo tem como objetivo apresentar uma proposta de discussão sobre alfabetização científica e tecnológica (ACT) pelo uso de roteiro de filmes de bilheteria contemporâneo. 0 filme selecionado "Eu Sou a Lenda" subsidiou um instrumento pedagógico no intuito de auxiliar o professor a proporcionar em seus alunos reflexões sobre o desenvolvimento cientifico e tecnológico. A aplicação do uso do roteiro ocorreu em uma turma de Engenharia de Produção Mecânica, quarto período de uma Universidade Tecnológica, no Paraná, contendo trinta e oito alunos participantes com idades entre 18 e 30 anos.
\end{abstract}

Palavras-chave: alfabetização cientifica e tecnológica, filmes comerciais, roteiros.

\begin{abstract}
This article is to present a proposal for discussion of scientific and technological literacy through the use of script grossing films of contemporary. Check the efficiency of the use of commercial film scripts, but precisely selected movie The movie I Am Legend, funded a teaching tool in order to help the teacher to provide students in their reflections on the scientific and technological development. The application of the use of the script was in a class of manufacturing engineering mechanics, fourth period of a Technological University in Paraná, containing thirty-eight students of participants aged 18 to 30 years.
\end{abstract}

Keywords: literacy scientific and technological, commercial films, screenplays.

\footnotetext{
${ }^{1}$ graduada em Tecnologia de Alimentos, Mestre em Educação Científica e Tecnológica - Universidade

Tecnológica Federal do Paraná - Campus Ponta Grossa. E-mail: manuellacandeo@gmail.com

2 professora de Educação em Ciências, graduada em Farmácia e Bioquímica, Doutora em Educação Universidade Tecnológica Federal do Paraná - Campus Ponta Grossa. E-mail: castilho@utfpr.edu.br

3 professora de língua portuguesa, Doutora em Educação - Universidade Tecnológica Federal do Paraná Campus Ponta Grossa. E-mail: elomatos@utfpr.edu.br
} 


\section{INTRODUÇÃo}

A utilização de filmes em sala de aula é uma prática bem conhecida de vários professores, o presente estudo busca a aplicação do filme em uma alternativa interdisciplinar, em que se utiliza o roteiro de um filme comercial de ficção cientifica, o filme Eu sou a lenda, lançado no ano de 2006, para proporcionar uma interação aluno professor e possibilitar a reflexão sobre o desenvolvimento cientifico e tecnológico, visando a ACT, alfabetização cientifica e tecnológica no ensino superior.

A alfabetização cientifica e tecnologia é extremamente importante, pois o avanço da ciência e da tecnologia ocorre de modo desenfreado, o que faz com que seja necessário investigar e questionar esse desenvolvimento e para isso as pessoas de maneira geral, precisa compreender quais são os verdadeiros interesses da ciência e da tecnologia, e quem esta por trás dela, para que haja uma participação dos cidadãos mais efetiva no desenvolvimento de novas tecnologias, compreendendo os múltiplos impactos que possam causar á sociedade.

O Homem sempre teve a necessidade de registrar suas vivencias, isso pode ser observado desde as pinturas rupestres presentes nas cavernas, marcas do homem primitivo. A 50000 a.c podemos citar o jogo de sombras criado no oriente, onde objetos eram recortados, e serviam para contar histórias por meio de suas sombras, representando dragões e princesas. Ressaltase o aparecimento da câmera escura, projeto desenvolvido por Leonardo da Vince, no século XV e desenvolvido pelo físico Gianbattista Della Porta no século XVI e a lanterna mágica criada pelo alemão Athanasius Kircher, estes dois aparatos tecnológicos proporcionaram as primeiras projeções.

Mais precisamente no século XIX algumas invenções foram criadas para auxiliar o homem nesta necessidade. Mas foi com os irmãos Lumiere na França que ocorreu a primeira projeção. O que marcou a virada do do século XIX. O cinema pode ser considerado a grande arte do século XX, e até os dias atuais ele faz parte da vida cotidiana das pessoas.

O cinema propôs ao espectador uma narrativa das cenas do cotidiano. Segundo Andrade (2004, p.17), 
[...] a narrativa cinematográfica desenvolveu-se a partir da constituição da linguagem do cinema, ainda no inicio do século XX, quando se evidenciou a possibilidade de manipulação do olhar, e surgiu a necessidade de ordenação das informações transmitidas através dos fragmentos das imagens, direcionando o espectador.

O cinema acabou por conquistar a conivência do espectador, por meio da busca de referências no cotidiano do homem, mostrando seu passado, presente, e intuindo o seu futuro. Silva Jr (2010) aponta que a trama esta que possa colocar o homem observador a uma distância física e emocional, capaz de fazê-lo se reconhecer como um ser histórico, sociológico, antropológico e cientifico. Desse modo o cinema em sala de aula é uma ferramenta que requer do educador competências e habilidades a partir de diversas fontes de linguagem, para Reali (2007) o "cinema pode ser considerado uma nova "máquina de ensinar", que pode ser trabalhada em sentido favorável a critica social e cultural de maneira madura, reunindo diferentes tipos de saberes relacionado ao conhecimento." Portando o cinema se transforma em uma riquíssima ferramenta de análise e reflexão e compreensão do mundo e da humanidade, podendo transformar-se em verdadeiro debate coletivo (REALI, 2007, p.135).

O cinema pode ser usado para proporcionar uma alfabetização cientifica e tecnológica pois esta tem sido cada vez mais necessária, principalmente devido aos avanços da ciência e da tecnologia, como a engenharia genética, medicina, robotização entre outros, a divulgação dos desenvolvimentos científicos e tecnológicos é extremamente necessária. Contudo como afirma Auler (2001 p.1),

[...] o rótulo Alfabetização Científica e Tecnológica abarca um espectro bastante amplo de significados traduzidos através de expressões como popularização da ciência, divulgação científica, entendimento público da ciência e democratização da ciência. Os objetivos balizadores são diversos e difusos. Vão desde a busca de uma autêntica participação da sociedade em problemáticas vinculadas à $\mathrm{CT}$, até aqueles que colocam a ACT na perspectiva de referendar e buscar o apoio da sociedade para a atual dinâmica do desenvolvimento científico-tecnológico. 
Corrobora-se com o autor que a ciência e a tecnologia devem ter uma participação democrática, no entanto como se pode fazer com que ocorra essa participação, se não alfabetizarmos cientifica e tecnologicamente o aluno? E alfabetizar cientifica e tecnologicamente, $\mathrm{Na}$ concepção de Hazel Hazel e Trefil (2005, p.12), “[...] é ter o conhecimento necessário para entender os debates públicos sobre as questões de ciência e tecnologia [...]“ O fato é que fazer ciência é inteiramente diferente de usar ciência. E a alfabetização científica refere-se somente ao uso da ciências.

Alfabetizar cientifica e tecnologicamente como definida por Chassot (2003) é saber ler e interpretar a linguagem relacionada e escrita na natureza, e que o analfabeto cientifico é aquele incapaz de ler o que está escrito no universo. Chassot ( 2003, p.94) ainda acrescenta que:

[...] seria desejável que os alfabetizados cientificamente não apenas tivessem facilitada leitura do mundo em que vivem, mas entendessem as necessidades de transformá-lo - e, preferencialmente, transformá-lo em algo melhor. Tenho sido recorrente na defesa da exigência de com a ciência melhorarmos a vida no planeta, e não torná-la mais perigosa, como ocorre, às vezes, com maus usos de algumas tecnologias.

Ser uma pessoa alfabetizada cientifica e tecnologicamente não significa ter todo o domínio da ciência e da tecnologia, pois isso seria impossível, mais sim saber avaliar os seus desenvolvimentos, é esse o objetivo dos roteiros de filmes comerciais como proposta para a ACT, promover nos alunos a oportunidade de parar e refletir sobre os avanços da ciência e da tecnologia. Podendo avaliar os benefícios e malefícios que lhes proporcionam. 


\section{PROCEDIMENTOS METODOLÓGICOS}

A pesquisa se caracteriza uma pesquisa aplicada, de cunho qualitativo em que se buscou testar a aplicação do uso do roteiro de um filme comercial com o objetivo de proporcionar uma ACT, nos alunos.

Para a aplicação do roteiro foi selecionado a turma de ensino superior curso engenharia de produção mecânica em uma Instituição Tecnológica Federal no Paraná, com trinta e oito alunos, entre 17 e 30 anos, que possuem em seu currículo escolar a disciplina de tecnologia e desenvolvimento, que tem em seu conteúdo referências voltadas ao CTS, ciência tecnologia e sociedade, que é o estudo das relações entre a Ciência a Tecnologia e a Sociedade.

Segundo Cerezo (2002), os estudos sobre ciência, tecnologia e sociedade (CTS) são, hoje, um campo de trabalho que busca entender o fenômeno científico-tecnológico no contexto social, tanto na relação com suas condicionantes sociais, quanto no que se refere às suas consequências sociais. $\mathrm{O}$ filme escolhido foi selecionado entre outros filmes e analisado observando-se a expressiva representatividade e atração ao público jovem e a temática do enredo que impulsionam uma visão de imbricações positivas e negativas do desenvolvimento da ciência e por conseguinte o aparecimento de tecnologia apropriada. Direcionou-se ao filme um olhar mais criterioso, para selecionar e analisar as cenas, que pudessem contribuir para uma reflexão voltada ao desenvolvimento cientifico e tecnológico, para a ACT.

Após a analise do filme, e seleção de cenas foi desenvolvido o seguinte roteiro, baseado no quadro: quadro 1, que relata os nove aspectos da abordagem CTS. 
Quadro 1. Os nove aspectos da abordagem de CTS.

\begin{tabular}{|c|c|}
\hline 1- Natureza da ciência & $\begin{array}{l}\text { 1- Ciência é uma busca de conhecimentos dentro de } \\
\text { uma perspectiva social. }\end{array}$ \\
\hline 2- Natureza da Tecnologia & $\begin{array}{l}\text { 2- Tecnologia envolve o uso do conhecimento } \\
\text { científico e de outros conhecimentos para resolver } \\
\text { problemas práticos. A humanidade sempre teve } \\
\text { tecnologia. }\end{array}$ \\
\hline 3- Natureza da Sociedade & $\begin{array}{l}\text { 3- A sociedade é uma instituição humana na qual } \\
\text { ocorrem mudanças científicas e tecnológicas. }\end{array}$ \\
\hline $\begin{array}{lrlll}4- & \text { Efeito da } & \text { Ciência } & \text { sobre } & a \\
\text { Tecnologia } & & & \end{array}$ & $\begin{array}{l}\text { 4-A produção de novos conhecimentos tem } \\
\text { estimulado mudanças tecnológicas. }\end{array}$ \\
\hline $\begin{array}{l}\text { 5- Efeito da Tecnologia sobre a } \\
\text { Sociedade }\end{array}$ & $\begin{array}{l}\text { 5-A tecnologia disponível a um grupo humano } \\
\text { influencia grandemente o estilo de vida do grupo. }\end{array}$ \\
\hline 6- Efeito da Sociedade sobre a Ciência & $\begin{array}{l}\text { 6-Por meio de investimentos e } \\
\text { outras pressões, a sociedade influencia a direção da } \\
\text { pesquisa científica. }\end{array}$ \\
\hline 7- Efeito da Ciência sobre a Sociedade & $\begin{array}{l}\text { 7- O desenvolvimento de teorias científicas pode } \\
\text { influenciar o pensamento das pessoas e as soluções } \\
\text { de problemas. }\end{array}$ \\
\hline $\begin{array}{l}\text { 8- Efeito da Sociedade sobre a } \\
\text { Tecnologia }\end{array}$ & $\begin{array}{l}\text { 8-Pressões dos órgãos públicos e de empresas } \\
\text { privadas podem influenciar a direção da solução do } \\
\text { problema e, em consequência, promover } \\
\text { mudanças tecnológicas. }\end{array}$ \\
\hline $\begin{array}{l}\text { 9- Efeito da Tecnologia sobre a } \\
\text { Ciência }\end{array}$ & $\begin{array}{l}\text { 9-A disponibilidade dos recursos tecnológicos } \\
\text { limitará ou ampliará }\end{array}$ \\
\hline
\end{tabular}

Fonte: Santos e Schnetzler (2003, p. 65). 
Analisando o quadro 1, pode-se perceber que o CTS pode ser trabalhado em qualquer ano letivo e em qualquer disciplina, o aprofundamento do conteúdo CTS depende do entrosamento dos alunos e do professor, que ministra a aula. A ACT vem com o intuito de instigar o aluno, para que ele possa questionar o desenvolvimento científico e tecnológico o que extrapola os muros da escola, podendo transformar o aluno em um cidadão mais participativo.

Segundo Osório (2002, p. 64),

[...] o enfoque educativo em CTS, tanto recupera os espaços críticos dessa relação conjunta ao desenvolver as implicações e os fins do desenvolvimento científico- tecnológico em um emaranhado social, político e ambiental, como se nos apresenta como um campo de análises propício para entender e educar o fenômeno tecnocientífico moderno.

O movimento CTS vem para despertar no aluno a curiosidade, o espírito de investigação, fazendo com que o aluno busque soluções para os problemas relacionados ao seu cotidiano, e que esse pensamento possa servir de forma útil a sua comunidade. Partindo das categorias mostradas no quadro 1, foi realizada uma análise do momentos do filme com articulações do enfoque CTS com as cenas exibidas no filme estudado (Quadro 2).

Assistiu-se ao filme com os alunos e em seguida abriu-se um debate em sala de aula motivado pelas questões expostas pelo roteiro. As reflexões e indagações dos alunos foram registradas em diário de campo. 
Quadro 2. Análise dos aspectos CTS nos momentos do filme cinematográfico.

\begin{tabular}{|c|c|c|}
\hline AS ASPECTOS CTS & CENA & ENVOLVIMENTO CTS \\
\hline Natureza da ciência & $\begin{array}{l}\text { Dra Elice Tripp fala em uma } \\
\text { reportagem sobre doenças na TV, } \\
\text { sobre a sua descoberta da " a cura } \\
\text { do câncer". Afirma que usou o vírus } \\
\text { do sarampo, modificado } \\
\text { geneticamente, e que com isso } \\
\text { conseouiucurar } 1000 \text { nessoas }\end{array}$ & $\begin{array}{l}\text { A ciência usada pela doutora Tripp, foi testada em um grande } \\
\text { número de cobaias humanas. O que você pensa sobre o uso de } \\
\text { cobaias humanas? }\end{array}$ \\
\hline $\begin{array}{l}\text { Efeito da Ciência sobre a } \\
\text { Sociedade }\end{array}$ & $\begin{array}{l}\text { Após um determinado tempo as } \\
\text { pessoas "curadas do câncer" com o } \\
\text { vírus do sarampo geneticamente } \\
\text { modificado, apresentaram sintomas } \\
\text { parecidos com o da raiva. }\end{array}$ & $\begin{array}{l}\text { Muitos produtos científicos são aplicados sem serem } \\
\text { devidamente testados. Você acredita que isso acontece nos dias } \\
\text { atuais? Você confia plenamente nas palavras dos cientistas? }\end{array}$ \\
\hline $\begin{array}{l}\text { Efeito da Tecnologia } \\
\text { sobre a Sociedade }\end{array}$ & $\begin{array}{l}\text { Após o vírus ter se espalhado, as } \\
\text { forças armadas resolvem realizar uma } \\
\text { quarentena na cidade. Então as } \\
\text { pessoas são escaneadas para ver se } \\
\text { são ou não portadoras do vírus. }\end{array}$ & $\begin{array}{l}\text { A esposa do Dr. Neville é detectada portadora do vírus, porém ao } \\
\text { repetir o escaneamento é detectada como sã. Houve falha no } \\
\text { equipamento, podendo prejudicar as pessoas. Nos dias atuais } \\
\text { como você vê essa falha? Onde ela ocorre? A culpa é da } \\
\text { tecnologia? }\end{array}$ \\
\hline $\begin{array}{l}\text { Efeito da Tecnologia } \\
\text { sobre a Sociedade }\end{array}$ & $\begin{array}{l}\text { Em uma de suas gravações } \\
\text { Dr. Neville, afirma que o } \\
\text { comportamento humano, desapareceu } \\
\text { dos doentes, e afirma que eles } \\
\text { perderam "seus instintos básicos de } \\
\text { sobrevivência", no entanto, Dr. Neville } \\
\text { é capturado pelos doentes. }\end{array}$ & $\begin{array}{l}\text { Dr. Neville se enganou ao afirmar que os doentes perderam } \\
\text { a capacidade de raciocinar. Até os melhores cientistas podem } \\
\text { errar? Como você enxerga este fato? }\end{array}$ \\
\hline $\begin{array}{l}\text { Efeito da Sociedade } \\
\text { sobre a Tecnologia }\end{array}$ & $\begin{array}{l}\text { O filme gira em torno do Dr. Neville, } \\
\text { que busca incansavelmente a cura da } \\
\text { doença. }\end{array}$ & $\begin{array}{l}\text { Muitas doenças têm suas curas descobertas pelo interesse dos } \\
\text { cientistas. Como você vê o interesse dos cientistas no que tange à } \\
\text { busca da cura de doenças? A descoberta da cura da doença } \\
\text { H1N1, um vírus totalmente novo, foi em questão de semanas. Por } \\
\text { que a descoberta da cura da malária que é uma doença que Ainda } \\
\text { provoca muitas mortes não foi descoberta? A ciência é neutra? }\end{array}$ \\
\hline $\begin{array}{l}\text { Efeito da Tecnologia } \\
\text { sobre a Ciência }\end{array}$ & $\begin{array}{l}\text { Apesar de ter todas as tecnologias a } \\
\text { seu alcance o Dr. Neville, não tem } \\
\text { com quem conversar e se sente } \\
\text { solitário. Isso se deve à devastação } \\
\text { da ilha onde mora. }\end{array}$ & $\begin{array}{l}\text { Hoje os seres humanos têm ainda mais } \\
\text { tecnologias, mas cada dia se isolam mais. Você acha que às } \\
\text { tecnologia é a responsável pelo isolamento humano? }\end{array}$ \\
\hline Outras questões & & $\begin{array}{l}\text { Outras questões que podem ser tratadas com o uso do filme são: } \\
\text { Remédios que não são devidamente testados. } \\
\text { - } \text { teenças causadas pelo desenvolvimento da ciência e da } \\
\text { Aumento do número de pessoas com doenças como o } \\
\text { câncer. } \\
\text { Cobaias humanas. Modificações genéticas. }\end{array}$ \\
\hline
\end{tabular}




\section{CONSIDERAÇÕES FINAIS}

Pode-se observar por meio do debate em sala de aula, que apenas $5 \%$ da classe havia assistido o filme, mesmo sendo um filme comercial do ano de $2006 \mathrm{com}$ atores conhecidos. Registrou-se o grande interesse por parte dos acadêmicos em relação ao filme, e quando questionados sobre a escolha do filme eu sou a lenda, 7\% destes se manifestaram afirmando que o filme é bom e prende a atenção, nenhum dos alunos se manifestou desfavorável ao filme.

Em relação ás respostas percebeu-se que 25\% dos jovens acredita fielmente na ciência e na tecnologia, defendendo os testes em cobaias humanas, argumentando que existem casos em que realmente é necessário como afirma a fala do aluno A1 “ se o cara esta morrendo, e vai morrer mesmo, fazer teste de medicamentos com ele, só vai ajudar a ciência, isso não é crime, pode até salvar a sua vida". Após esse comentário grande parte dos alunos acabou concordou o que gerou discussão em sala de aula, pois antes eles haviam afirmado ser contra o teste em humanos.

O foco do debate acabou mudando para o lado da confiança na ciência e na tecnologia, voltando o questionamento sobre a neutralidade da ciência, deu início a uma discussão sobre o uso de vacinas contra a gripe, e o uso de remédios indicados por médicos. Mesmo apresentando alguns casos de mortes por erros médicos, $90 \%$ dos alunos que se manifestaram concordaram com a fala do aluno A2 "se a gente não for confiar nos médicos, vai confiar em quem? Se ele que estudou pra isso não souber como tratar os pacientes, quem que vai saber?"

Esta fala do aluno, nos mostra o quanto a sociedade se encontra incipiente diante de questões referentes a ciência e a tecnologia. Sobre a discussão voltada a tecnologia, principalmente as suas falhas o tema começou quando um dos participantes aluno A3 destacou o "recall" de carros com defeitos, afirmando "[...] quando mandam o carro voltar pra conceciossionária por causa de defeito, e dão algum brinde, ficamos contentes, não pensamos que aquele defeito no carro podia acabar matando a gente [...]". Esta fala fez com que a turma refletisse sobre como somos manipulados, por quem possui o domínio da ciência e da tecnologia. 
Em avaliação geral os resultados obtidos com o debate, foram extremamente proveitosos, no entanto mostraram, que os alunos participantes da pesquisa, ainda enxergam a ciência e a tecnologia e quem as domina como entes separados das vontades da humanidade, sendo neutros e intactos, e que sim, podem salvar a civilização, pois apenas fazem o bem ás pessoas. Com o auxilio do filme foi possível proporcionar uma reflexão sobre estas questões.

Para abordagem mais completamente este tema prosseguiu-se com o apoio de leituras para desencadear subsunçores efetivos a discussões, cada vez mais esclarecedoras e amostragem de outros filmes. Note-se que a promoção da ACT e um caminho que demanda exploração de diversos contextos para que o acadêmico estabeleça as correlações e se posicione criticamente.

Napolitano(2009, p.14) afirma que,

[...] nada impede o professor e o pesquisador de utilizarem um filme como documento para pensar a sociedade, a história, as ciências, a linguagem. Mas, antes de tudo, um filme é um filme, um documento diferente do texto escrito, da iconografia, do gráfico. Um filme é um ramo da Arte que não é um livro, um quadro, uma peça musical ou teatral, embora possa dialogar com todos esses veículos e linguagens.

O professor tem o cinema a seu alcance e pode usar ele em sala de aula, como uma ferramenta que estimula o aprendizado.

A escolha de um filme comercial foi idealizada para proporcionar ao acadêmico uma forma mais atrativa, por ser um filme de ação e com um ator conhecido, os alunos demostram mais interesse e ficara mais atentos a sessão, como se evidenciou esta pesquisa. 0 desenvolvimento de um roteiro proporciona ao professor melhor domínio sobre o debate em sala de aula, não deixando se perder o foco que é o ACT.

O uso do roteiro do filme comercial, para promover a ACT, é um eficiente método, no entanto faz-se mister na promoção da ACT, é necessário o uso de abordagens complementares e mais 


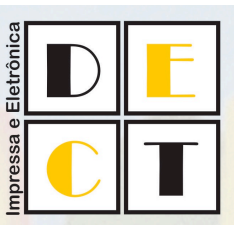

detalhada sobre o tema com os acadêmicos. Reforçando-os com leituras específicas e discussões contínuas, levando o acadêmico a apropriar-se de uma significação ampla do contexto em que está inserido. Resinificando-o e assim se posicionado de maneira crítica e consciente, elaborando com propriedade a leitura do mundo científico e tecnológico.

\section{REFERÊNCIAS}

ANDRADE, Ana Lucia. Entreterimento inteligente: o cinema de Billy Wilder, Belo Horizonte: Editora UFMG, 2004.

AULER1[1] Décio; Delizoicov Demétrio, ALFABETIZAÇÃo CIENTÍFICO- TECNOLÓGICA PARA QUÊ? ENSAIO - Pesquisa em Educação em Ciências- Volume 03 / Número 1 - Jun. 2001.

CEREZO J. A. Ciência, Tecnologia e Sociedade: o estado da arte na Europa e nos Estados Unidos. In: SANTOS, Lucy W. Dos; ICHIKAWA, Elisa Y.; SENDIN Paulo V.; CARGANO, Doralice de F (Org.). Ciencia, Tecnologia e Sociedade: o desafio da interação. Londrina: IAPAR, pp. 03-39. 2002.

CHASSOT, Attico. Alfabetização Científica: uma possibilidade para a inclusão social. Revista Brasileira de Educação, jan./fev./mar/abr., n 22, 89-100, 2003.

HAZEN, Robert M. e TREFIL, James. Saber Ciências. São Paulo: Editora de Cultura, 2005.

NAPOLITANO, M. Caderno de cinema do professor: dois, Secretaria da Educação, fundação para o desenvolvimento da educação. São Paulo: FDE, 2009.

OSORIO, Carlos Osorio M. La Educación Científica y Tecnológica desde el enfoque em Ciencia, Tecnología y Sociedad. Aproximaciones y Experiencias para laEducación Secundaria. Enseñanza de laTecnología / Ensino da Tecnología, no28, enero-abril 2002.

REALI, Noeli Gemelli, Cinema: a aula outra: in: Reali, N. G. ( org). Cinema na Universidade: possibilidades, diálogos e diferenças. Chapecó: Argos, 2007.

SANTOS, W. L. P.; SCHNETZLER, R. P. Educação em química: compromisso com a cidadania. Ijuí: Editora da Unijuí, 1997.

SILVA JR, Nelson, IX, O cinema como proposta Interdisciplinar na sala de aula; uma reflexão em cena, arte e ciência: um encontro interdisciplinar, editora Maringá, 2010. 